\title{
The atmospheric implications of radiation belt remediation
}

\author{
C. J. Rodger ${ }^{1}$, M. A. Clilverd ${ }^{2}$, Th. Ulich $^{3}$, P. T. Verronen ${ }^{4}$, E. Turunen ${ }^{3}$, and N. R. Thomson ${ }^{1}$ \\ ${ }^{1}$ Department of Physics, University of Otago, Dunedin, New Zealand \\ ${ }^{2}$ Physical Sciences Division, British Antarctic Survey, Cambridge, UK \\ ${ }^{3}$ Sodankylä Geophysical Observatory, Sodankylä, Finland \\ ${ }^{4}$ Finnish Meteorological Institute, Helsinki, Finland
}

Received: 3 April 2006 - Accepted: 23 June 2006 - Published: 9 August 2006

\begin{abstract}
High altitude nuclear explosions (HANEs) and geomagnetic storms can produce large scale injections of relativistic particles into the inner radiation belts. It is recognised that these large increases in $>1 \mathrm{MeV}$ trapped electron fluxes can shorten the operational lifetime of low Earth orbiting satellites, threatening a large, valuable population. Therefore, studies are being undertaken to bring about practical human control of the radiation belts, termed "Radiation Belt Remediation" (RBR). Here we consider the upper atmospheric consequences of an RBR system operating over either 1 or 10 days. The RBR-forced neutral chemistry changes, leading to $\mathrm{NO}_{\mathrm{x}}$ enhancements and $\mathrm{O}_{\mathrm{x}}$ depletions, are significant during the timescale of the precipitation but are generally not long-lasting. The magnitudes, time-scales, and altitudes of these changes are no more significant than those observed during large solar proton events. In contrast, RBR-operation will lead to unusually intense HF blackouts for about the first half of the operation time, producing large scale disruptions to radio communication and navigation systems. While the neutral atmosphere changes are not particularly important, HF disruptions could be an important area for policy makers to consider, particularly for the remediation of natural injections.
\end{abstract}

Keywords. Magnetospheric physics (Energetic particles, precipitating; Magnetosphere-ionosphere interactions) Ionosphere (Active experiments)

\section{Introduction}

The behaviour of high energy electrons trapped in the Earth's Van Allen radiation belts has been extensively studied, through both experimental and theoretical techniques. During quiet times, energetic radiation belt electrons are

Correspondence to: C. J. Rodger

(crodger@physics.otago.ac.nz) distributed into two belts divided by the "electron slot" at $L \sim 2.5$, near which there is relatively low energetic electron flux. In the more than four decades since the discovery of the belts (Van Allen et al., 1958; Van Allen, 1997), it has proven difficult to confirm the principal source and loss mechanisms that control radiation belt particles (Walt, 1996). It is well known that large scale injections of relativistic particles into the inner radiation belts are associated with geomagnetic storms which can result in a $10^{5}$-fold increase in the total trapped electron population of the radiation belts ( $\mathrm{Li}$ and Temerin, 2001). In some cases the relativistic electron fluxes present in the radiation belts may increase by more than two orders of magnitude (Reeves et al., 2003). In most cases, however, these injections do not penetrate into the inner radiation belt. Only in the biggest storms, for example November 2003, does the slot region fill and the inner belt gain a new population of energetic electrons (e.g., Baker et al., 2004).

Even before the discovery of the radiation belts, high altitude nuclear explosions (HANEs) were studied as a source for injecting electrons in the geomagnetic field. This was confirmed by the satellite Explorer IV in 1958, when three nuclear explosions conducted under Operation Argus took place in the South Atlantic, producing belts of trapped electrons from the $\beta$-decay of the fission fragments. The trapped particles remained stable for several weeks near $L=2$, and did not drift in $L$ or broaden appreciably (Hess, 1968). Following on from Operation Argus, both the US and USSR conducted a small number of HANEs, all of which produced artificial belts of trapped energetic electrons in the Earth's radiation belts. One of the most studied was the US "Starfish Prime" HANE, a 1.4 Megaton detonation occurring at $400 \mathrm{~km}$ above Johnston Island in the central Pacific Ocean on 9 July 1962. Again an artificial belt of trapped energetic electrons was injected, although over a wide range of L-shells from about $L=1.25$ out to perhaps $L=3$ (Hess, 1968). The detonation also caused artificial aurora observed as far

Published by Copernicus GmbH on behalf of the European Geosciences Union. 
away as New Zealand, and an electromagnetic pulse which shut down communications and electrical supply in Hawaii, $1300 \mathrm{~km}$ away (Dupont, 2004).

The effect of the Starfish Prime HANE on the radiation belts was observed by multiple spacecraft. However, the intense artificial belts injected by the HANE damaged 3 of the 5 satellites operating at the time. Within a small number of days, data transmissions from the Ariel, Transit IVB and TRAAC satellites became intermittent or ceased altogether (Massey, 1964), primarily due to degrading solar cells. Other effects were also noted even in this early case; the transistors flown in the first active communications satellite, Telstar, failed due to radiation exposure, even though the satellite was launched after the Starfish Prime HANE.

The artificial belts produced by this Starfish Prime HANE allowed some understanding of the loss of energetic electrons from the radiation belts, as demonstrated by the comparison of calculated decay rates with the observed loss of injected electrons (Fig. 7.3 of Walt (1994)). Collisions with atmospheric constituents are the dominant loss process for energetic electrons $(>100 \mathrm{keV})$ only in the inner-most parts of the radiation belts $(L<1.3)$ (Walt, 1996). For higher L-shells, radiation belt particle lifetimes are typically many orders of magnitude shorter than those predicated due to atmospheric collisions, such that other loss processes are clearly dominant. Above $L \sim 1.5$ coulomb collision-driven losses are generally less important than those driven by whistler mode waves, including plasmaspheric hiss, lightning-generated whistlers, and manmade transmissions (Abel and Thorne, 1998, 1999; Rodger et al., 2003).

It is recognised that HANEs would shorten the operational lifetime of Low Earth Orbiting satellites (Parmentola, 2001; U.S. Congress, 2001; Steer, 2002), principally due to the population of HANE-injected $>1 \mathrm{MeV}$ trapped electrons. It has been suggested that even a "small" HANE $(\sim 10$ 20 kilotons) occurring at altitudes of $125-300 \mathrm{~km}$ would raise peak radiation fluxes in the inner radiation belt by 3-4 orders of magnitude, and lead to the loss of $90 \%$ of all lowearth-orbit satellites within a month (Dupont, 2004). In 2004 there were approximately 250 satellites operating in low-Earth orbit (LEO) (Satellite Industry Association, 2004). These satellites fulfil a large number of roles, including communications, navigation, meteorology, military and science. In the event of a HANE, or an unusually intense natural injection, this large population of valuable satellites would be threatened. Due to the lifetime of the injected electrons, the manned space programme would need to be placed on hold for a year or more. However, recent theoretical calculations have led to the rather surprising conclusion that wave-particle interactions caused by manmade very low frequency (VLF) transmissions may dominate non-storm time losses in the inner radiation belts (Abel and Thorne, 1998; 1999). This finding has sparked considerable interest, suggesting practical human control of the radiation belts (Inan et al., 2003) to protect Earth-orbiting systems from natural and manmade injections of high energy electrons. This manmade control of the Van Allen belts has been termed "Radiation Belt Remediation" (RBR). An RBR-system would probably involve a constellation of perhaps 10 satellites (Dupont, 2004), which would transmit VLF waves so as to vastly increase the loss-rate of energetic electrons by precipitation into the upper atmosphere, essentially dumping the HANE-produced artificial radiation belt. In order to be effective, an RBRsystem needs to flush the HANE-produced $1 \mathrm{MeV}$ electrons in a short time scale, which has been suggested to be as low as $\sim 1-2$ days or perhaps as long as 10 days (Papadopoulos, 2001).

In this paper we consider the upper atmospheric consequences of an RBR system in operation. The dumping of high-energy relativistic electrons into the atmosphere will create intense energetic particle precipitation, leading to large ionisation changes in the ionosphere. Such precipitation is likely to lead to large changes in atmospheric chemistry and communications disruption, particularly for the case of HANE injections. Particle precipitation results in enhancement of odd nitrogen $\left(\mathrm{NO}_{\mathrm{x}}\right)$ and odd hydrogen $\left(\mathrm{HO}_{\mathrm{x}}\right) . \mathrm{NO}_{\mathrm{x}}$ and $\mathrm{HO}_{\mathrm{x}}$ play a key role in the ozone balance of the middle atmosphere because they destroy odd oxygen through catalytic reactions (e.g., Brasseur and Solomon, pp. 291-299, 1986). Ionisation changes produced by a $1 \mathrm{MeV}$ electron will tend to peak at $\sim 55 \mathrm{~km}$ altitude (Rishbeth and Garriott, 1969). Ionisation increases occurring at similar altitudes, caused by solar proton events are known to lead to local perturbations in ozone levels (Verronen et al., 2005). Changes in $\mathrm{NO}_{\mathrm{x}}$ and $\mathrm{O}_{3}$ consistent with solar proton-driven modifications have been observed (Seppälä et al., 2004, Verronen et al., 2005). It is well-known that the precipitation of electrons at high latitudes produce addition ionisation leading to increased HF absorption at high-latitudes (MacNamara, 1985), in extreme cases producing a complete blackout of $\mathrm{HF}$ communications in the polar regions.

In order to estimate the significance of RBR-driven precipitation to the upper atmosphere, we consider two cases of an RBR-system operating to flush the artificial radiation belt injected by a Starfish Prime-type HANE over either 1 or 10 days. In the first case we consider the effect of a spacebased system, while in the second case we also consider a ground-based RBR system. This work examines the range of realistic potential environmental and technological effects due to this manmade precipitation, including changes to the ozone-balance in the middle atmosphere, and disruption to HF communication.

\section{HANE-produced trapped electrons}

The injection caused by the 1.4 megaton Starfish Prime HANE was extensively studied and reported upon in the open literature. While this HANE was undertaken with the express purpose of injecting energetic electrons into the radiation 


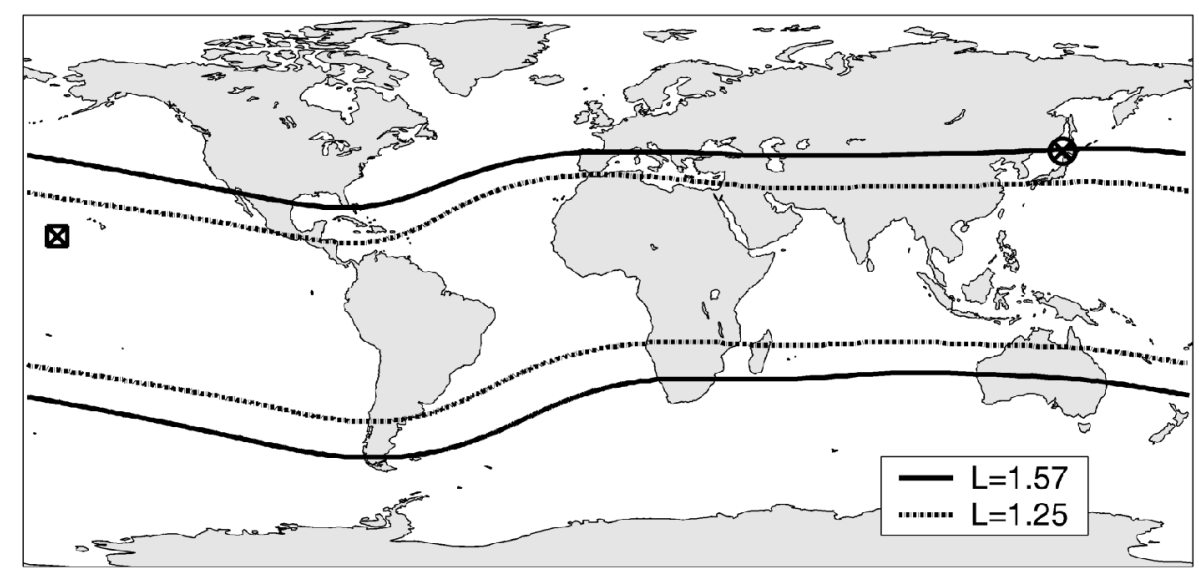

Fig. 1. Map showing the important locations in our study. The original Starfish Prime HANE occurred above Johnston Island (square), while our SIC modelling points are above the city of Sapporo (circle at $L=1.57$ ). The $100 \mathrm{~km}$ footprints of the IGRF determined $L=1.25$ and $L=1.57$ are also shown.

belts, it occurred only 4 years after the discovery of the radiation belts, and in the earliest days of the Space Age. It is expected that a carefully planned modern HANE caused by a relatively small nuclear weapon $(\sim 15$ kiloton $)$ delivered to relatively low altitudes (a few $100 \mathrm{~km}$ ) might produce rather similar effects to Starfish Prime. Nonetheless, as noted above, we consider the Starfish Prime HANE as an extreme example for which reliable information is available. Figure 1 shows a map of the important locations in our study. The Starfish Prime HANE occurred above Johnston Island $\left(16.74^{\circ} \mathrm{N}, 169.52^{\circ} \mathrm{W}\right)$, shown in Fig. 1 by the square.

A HANE produces energetic particles at one point in space. However, within seconds those particles are distributed along the geomagnetic field line which passes through the HANE location, and within a few hours those particles drift around the Earth. The latter motion will cause the HANE-produced injection to spread in longitude, and hence fill the L-shell with an artificial radiation belt of relatively constant flux. In practice, a HANE need not affect a single L-shell. While the Operation Argus HANE led to artificial radiation belts which were only $\sim 100 \mathrm{~km}$ thick, the Starfish Prime HANE injected electrons into a wide range of L-shells.

At the lowest L-shells the Starfish Prime HANE injected energetic electrons into the radiation belt with an energy spectrum from $0-10 \mathrm{MeV}$ that was linearly proportional to the equilibrium-fission spectrum (Hess, 1963; Van Allen et al., 1963)

$$
\exp \left(-0.575 E-0.055 E^{2}\right) \text {, }
$$

where $E$ is in $\mathrm{MeV}$. This represents the spectrum of electrons from thermal neutron fission of $\mathrm{U}^{235}$ (Carter et al., 1959). This spectrum holds at $L=1.25$, but at higher L-shells the observed spectrum was found to be considerably softer. However, at $L=1.25$ the mean lifetime of $\sim 2 \mathrm{MeV}$ electrons is very short ( $\sim 30$ days) due to collisions with atmospheric constituents. In contrast, electrons of the same energy have a lifetime of $\sim 1$ year at $L \sim 1.5$ (Hess, Fig. 5.24, 1968), for the case of "natural" loss processes unassisted by an RBRsystem. It is these long-lived electrons which will strongly reduce the survivability of LEO satellites, and hence would be the focus for a future RBR-system. We therefore focus on the RBR-driven artificial precipitation of HANE-injection electrons around $L \sim 1.5$.

The injected electron spectrum softens as the bubble produced by the HANE expands (Hess, 1968), given by

$N\left(E_{0}\right) d E_{0}=\frac{l}{l_{0}} N\left(\frac{l_{0} E_{0}}{l}\right) d E$,

where $E_{0}$ and $l_{0}$ are the initial particle energy and bubble radius, and $N\left(E_{0}\right)$ describes the energy spectrum at an energy $E_{0}$. For $L=1.57$ a doubling in the bubble radius (i.e., $l / l_{0}=2$ ) produced the experimentally observed softening in the spectrum (Hess, 1968). Five days after the explosion, in situ measurements of the Starfish Prime HANE-injected $>0.5 \mathrm{MeV}$ omnidirectional integral electron fluxes indicated that the equatorial flux was fairly constant with $L$, with a value of $\sim 10^{9}$ electrons $\mathrm{cm}^{-2} \mathrm{~s}^{-1}$ from $L=1.25-1.7$. Figure 2 shows the equatorial omnidirectional differential electron flux at $L=1.25$ and $L=1.57$ based on these observations of the injection from the Starfish Prime HANE. Contours showing the International Geomagnetic Reference Field (GRF) determined footprints of $L=1.25$ and $L=1.57$ at $100 \mathrm{~km}$ altitude are shown in Fig. 1. Note the softening of the trapped equatorial electron spectrum from the equilibrium-fission spectrum at $L=1.25$ to the considerably different spectrum at $L=1.57$ due to the doubling in the HANE-produced bubble radius. Note also that the $L=1.57$ spectrum appears to have $\sim 4$ times more flux at the lowest energies than the $L=1.25$ spectrum. This is a consequence of the observed $>0.5 \mathrm{MeV}$ 


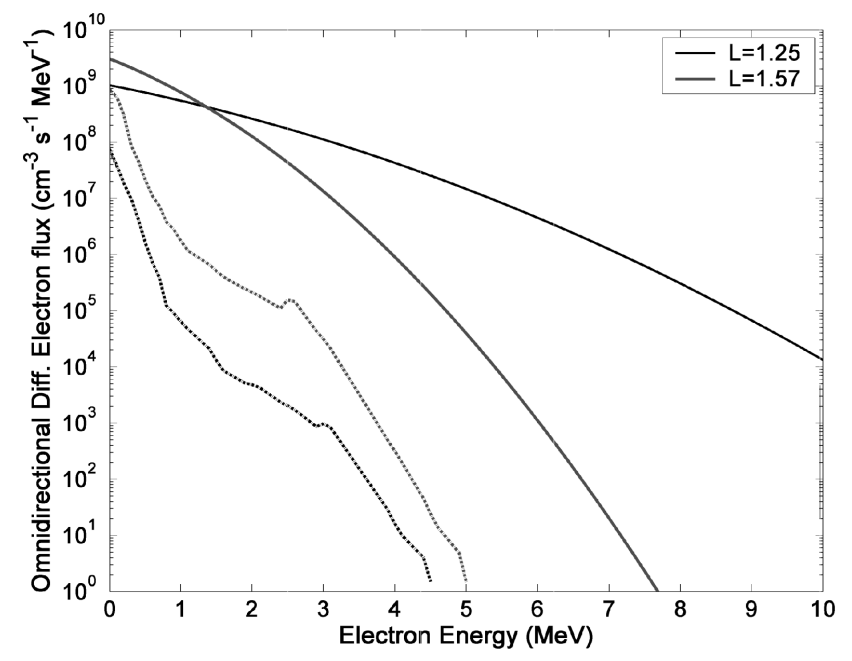

Fig. 2. The post-Starfish Prime HANE radiation belt environment in the inner radiation belt, showing the equatorial omnidirectional differential electron flux. Note the softening of the trapped equatorial electron spectrum from an equilibrium-fission spectrum (at $L=1.25$ ) with the expansion of the HANE produced bubble The dotted lines show the ambient trapped population from the ESA-SEE1 model.

omnidirectional integral electron flux being equal at the two L-shells, and the softening with increasing $L$. As the energy spectrum softens with the expansion of the HANE-produced bubble, a larger relative low-energy population is expected at high $L$ for the same omnidirectional integral electron flux. The "undisturbed" omnidirectional differential electron flux is shown by the dotted lines in Fig. 2, produced by the current standard trapped electron model for solar minimum conditions, ESA-SEE1 (Vampola, 1996). This is an update to AE-8MIN (Vette, 1991), and is described in more detail below. The small discontinuities (e.g., at $\sim 3 \mathrm{MeV}$ at $L=1.57$ ) are present in both the ESA-SEE1 and AE-8MIN model, and have been checked against the AE-8MIN model which can be run online at the National Space Science Data Centre website.

How does the Starfish Prime electron injection compare with those estimated for a carefully planned modern HANE, available from the open literature? The $>1 \mathrm{MeV}$ omnidirectional integral electron fluxes derived from Fig. 2 can be contrasted with the $>1 \mathrm{MeV}$ fluxes predicted for "normal" conditions from ESA-SEE1. These Starfish Prime HANE injections are $\sim 2.9 \times 10^{4}$ larger than AE-8MIN at $L=1.25$ and $\sim 5.7 \times 10^{2}$ larger at $L=1.57$. This is similar to the reported effect of a possible future HANE, i.e., a 3-4 order of magnitude increase in fluxes in the inner radiation belt (Parmentola, 2001; DuPont, 2004), especially when taking into account the suggested error estimates for AE-8 of "about a factor of 2" (Vette, pp. 4-2, 1991). However, it does suggest that the historic reports of the Starfish Prime HANE injections may not represent an extreme case, and instead is similar to the in- jections expected for a carefully planned future HANE using a much lower-yield weapon.

In our study we will use the HANE-modified equatorial omnidirectional differential electron fluxes shown in Fig. 2, taken from Starfish Prime, to consider the downstream implications of an RBR-system operating to flush out this energetic population.

\section{Sodankylä ion chemistry model}

Using the Sodankylä Ion Chemistry (SIC) model we consider the atmospheric consequences of an RBR system in operation. Dumping high energy electrons into the atmosphere will change atmospheric chemistry through changes in $\mathrm{HO}_{\mathrm{x}}$ and $\mathrm{NO}_{\mathrm{x}}$. The Sodankylä Ion Chemistry (SIC) model is a 1$\mathrm{D}$ chemical model designed for ionospheric D-region studies, solving the concentrations of 63 ions, including 27 negative ions, and 13 neutral species at altitudes across $20-150 \mathrm{~km}$. Our study made use of SIC version 6.6.0. The model has recently been discussed by Verronen et al. (2005), building on original work by Turunen et al. (1996) and Verronen et al. (2002). A detailed overview of the model was given in Verronen et al. (2005), but we summarize in a similar way here to provide background for this study.

In the SIC model several hundred reactions are implemented, plus additional external forcing due to solar radiation $(1-422.5 \mathrm{~nm})$, electron and proton precipitation, and galactic cosmic radiation. Initial descriptions of the model are provided by Turunen et al. (1996), with neutral species modifications described by Verronen et al. (2002). Solar flux is calculated with the SOLAR2000 model (version 2.21) (Tobiska et al., 2000). The scattered component of solar Lyman- $\alpha$ flux is included using the empirical approximation given by Thomas and Bowman (1986). The SIC code includes vertical transport (Chabrillat et al., 2002) which takes into account molecular diffusion coefficients (Banks and Kockarts, 1973). The background neutral atmosphere is calculated using the MSISE-90 model (Hedin, 1991) and Tables given by Shimazaki (1984). Transport and chemistry are advanced in intervals of 5 or $15 \mathrm{~min}$, while within each interval exponentially increasing time steps are used because of the wide range of chemical time constants of the modelled species.

\subsection{RBR forcing}

We use the SIC model to produce ionisation rates as outlined by Turunen et al. (1996) (based on the method of Rees (1989)). Hence we examine the altitude and time variation in neutral atmospheric species (e.g., $\mathrm{NO}_{\mathrm{x}}\left(\mathrm{N}+\mathrm{NO}+\mathrm{NO}_{2}\right)$, $\mathrm{HO}_{\mathrm{x}}\left(\mathrm{OH}+\mathrm{HO}_{2}\right)$, and $\left.\mathrm{O}_{\mathrm{x}}\left(\mathrm{O}+\mathrm{O}_{3}\right)\right)$, as well as the electron density profile. The SIC model is run for the location of Sapporo, Japan $\left(43^{\circ} \mathrm{N}, 140^{\circ} \mathrm{E}\right)$ starting at the vernal equinox in 2001. As seen in Fig. 1, this location is essentially on 
the $L=1.57$ contour for which Starfish Prime measurements exist, as discussed in Sect. 2. The choice of Sapporo as the SIC-modelling point is essentially arbitrary, and was selected in recognition of the city having hosted the IUGG conference in 2003, when we first discussed this collaboration.

We then assume an operational space-based RBR-system which operates to "flush" the HANE-injected energetic electrons into the upper atmosphere, so that the flux of $1 \mathrm{MeV}$ trapped electrons in a magnetic flux tube is driven down to within twice the ambient levels over a specified time period. In order to determine the precipitation into the upper atmosphere caused by the RBR-system, we need to consider the HANE-modified flux tube electron population. The flux tube electron population at a given $L$ and energy $E$ is found by first determining the differential number of electrons in a magnetic flux tube of 1 square centimetre in area at the equator plane, $N(E, L)$, given by

$$
\begin{aligned}
& N(E, L)= \\
& \quad \int_{0}^{\pi / 2} j_{e q}\left(\alpha_{e q}, E\right) \tau_{b}\left(\alpha_{e q}, E\right) 2 \pi \cos \alpha_{e q} \sin \alpha_{e q} d \alpha_{e q},
\end{aligned}
$$

where $j_{e q}$ is the HANE-modified differential directional electron flux in the equatorial plane, $\alpha_{e q}$ is the equatorial electron pitch angle, and $\tau_{b}$ is the full bounce period (Voss et al., 1998). The differential number of electrons in a tube having $1 \mathrm{~cm}^{2}$ area perpendicular to $\mathbf{B}$ at the top of the atmosphere, $N_{100 \mathrm{~km}}(E, L)$, is obtained by multiplying the equatorial density from Eq. (3) by the ratio of the magnetic field magnitude at $100-\mathrm{km}$ altitude to that at the equator. This provides the initial flux tube electron population at a given energy in a magnetic tube having one square centimetre cross section perpendicular to $\mathbf{B}$ at $100 \mathrm{~km}$.

We assume that the HANE-injected electrons will have a pitch-angle distribution which is much like that of the undisturbed radiation belt population, as reported for the Starfish Prime-injected electrons (Teague and Vette, 1972). The equatorial differential directional electron flux is determined by combining the differential omnidirectional electron fluxes of the ESA-SEE1 electron radiation belt model with the CRRES-satellite observed pitch angle dependences (Vampola, 1996) for $3<L<6.75$ and those from the earlier empirical AE-5 radiation belt model (Teague and Vette, 1972). Extrapolations and interpolations have been employed to smoothly join the pitch angle dependences between these two models. The ESA-SEE1 model is an update to AE$8 \mathrm{MIN}$ in which neural networks were trained to predict the CRRES Medium Electrons A (MEA) electron spectrometer flux at five energies $(148,412,782,1178$, and $1582 \mathrm{keV})$ at each of six $L$-values $(3,4,5,6,6.5$, and 7$)$ using the dailysum $K_{p}$. Average fluxes from the trained networks agree with the MEA data to within 15\% (mission-average, worst case network). Published spectra from the OV1-19 electron spectrometer (Vampola et al., 1977) were used to extend the

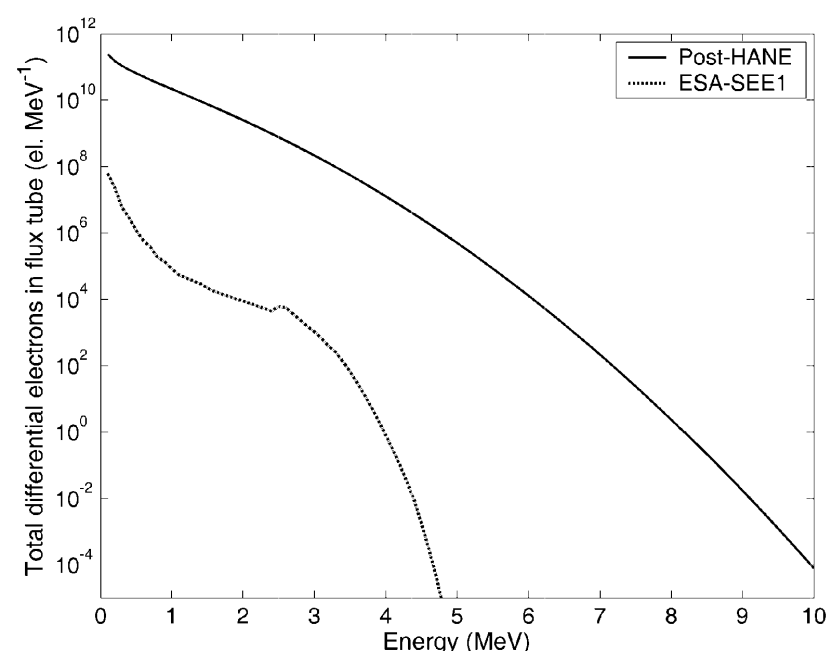

Fig. 3. The differential number of electrons in a tube at $L=1.57$ having $1 \mathrm{~cm}^{2}$ area perpendicular to $\mathbf{B}$ at $100 \mathrm{~km}$ altitude, $N_{100 \mathrm{~km}}(E, L)$, after the injection of energetic electrons from a HANE (sold line), and that predicted for undisturbed conditions from the ESA-SEE1 trapped electron model (dash-dot line).

neural network energy spectra down to $40 \mathrm{keV}$ and up to $7 \mathrm{MeV}$. The ESA-SEE1 model is a major improvement upon AE-8 at high energies. In contrast to ESA-SEE1 for energies $>2 \mathrm{MeV}$ the "AE- 8 model is not based on reliable data and is an extrapolation of unknown validity" (Vampola, 1996).

Figure 3 shows the $L=1.57$ flux tube electron population, $N_{100 \mathrm{~km}}(E, L)$ (solid line), after the injection of energetic electrons from a HANE as shown in Fig. 2. This is contrasted with the ESA-SEE1 model prediction for the same flux tube population in undisturbed conditions (dash-dot line). For most energies the ratio of the HANE-injected flux tube population to the undisturbed population is $10^{4}-10^{5}$, although this clearly increases a great deal for energies $>3 \mathrm{MeV}$ where the undisturbed population is extremely small.

We assume that the RBR-system will precipitate the HANE-injected electrons with an e-folding time such that the flux tube population at $1 \mathrm{MeV}, N_{100 \mathrm{~km}}(E=1 \mathrm{MeV}, L=1.57)$, is decreased to within twice the ESA-SEE1 value over a specified time period. For example, for the HANE-injected electrons to be returned to the normal population-level over 1 day, an e-folding time of 0.08 day $(\sim 2 \mathrm{~h})$ is required, while to achieve the same effect over 10 days an e-folding of time of 0.8 days $(\sim 19 \mathrm{~h})$ is needed. We make the rather gross assumption that the RBR-driven precipitation rate for $1 \mathrm{MeV}$ electrons will be the same for all other energies. In practice, the loss rate will be considerably more complex, and will be an important feature in the design of the RBR-system. Nonetheless, this approximation allows us to provide an estimate of the impact of the precipitation.

Figure 4 shows how the differential omnidirectional trapped flux at $L=1.57$ caused by the HANE will change 

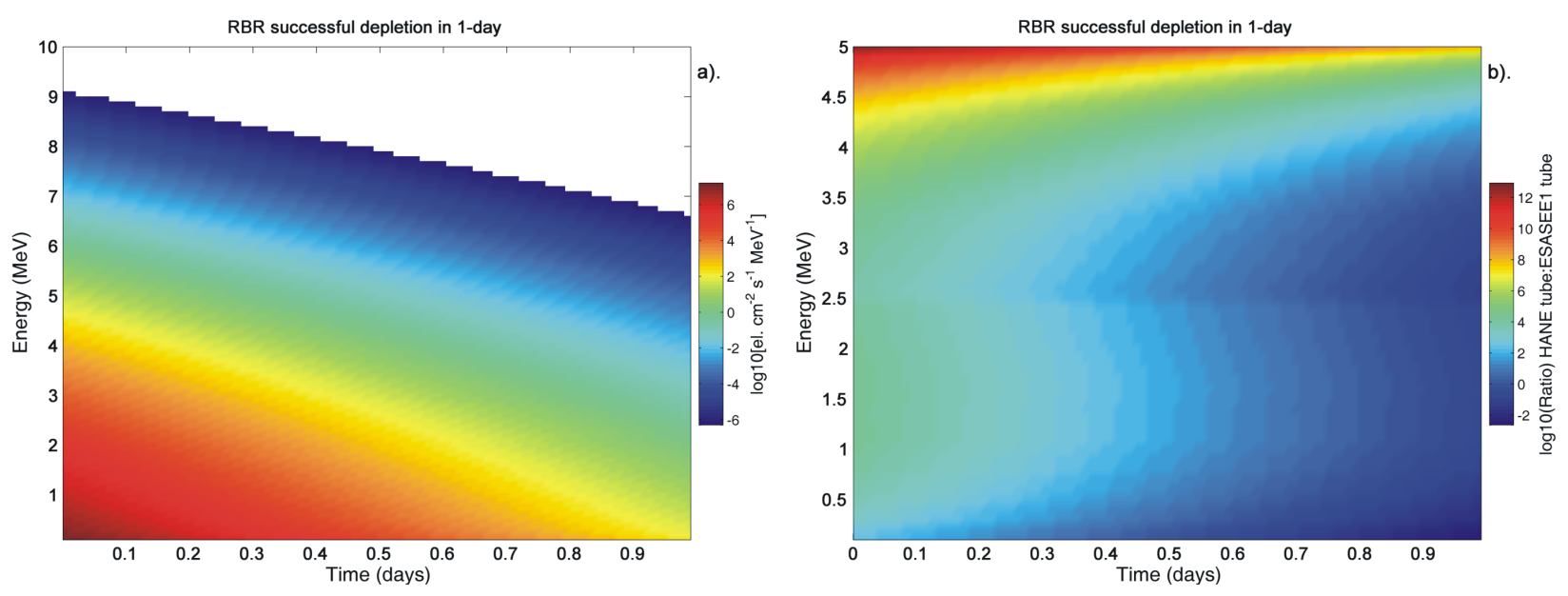

Fig. 4. The changing HANE-injected differential flux at $L=1.57$ during the operation of the assumed RBR-system. Here the injected population drops to ambient levels at $1 \mathrm{MeV}$ in 1 day. a). The changing differential omnidirectional trapped flux. b). The logarithm of the ratio of the differential omnidirectional trapped flux to the ESA-SEE1 predicted ambient level.

with our assumed RBR-system, for the case where the HANE-injected electrons are successfully flushed into the upper atmosphere over 1 day. The left-hand panel of Fig. 4 shows the changing differential omnidirectional trapped flux, while the right-hand panel displays the ratio of the differential omnidirectional trapped flux to that predicted by the ESA-SEE1 model. Note that the energy range in the righthand panel has a maximum value of $5 \mathrm{MeV}$. While the HANE injects electrons with energies $>5 \mathrm{MeV}$, as shown in Fig. 2, there is no trapped population at these energies. This is also the reason for the extremely high ratio between the HANE-injected and "normal" fluxes in this panel for energies $\sim 5 \mathrm{MeV}$. For the other time-scale we consider, where the HANE-injected electrons are successfully flushed into the upper atmosphere over 10 days, Fig. 4 will be identical except that the time scale on both plots is scaled by a factor of 10 .

The electrons lost from the flux tube are assumed to be precipitated into the upper atmosphere of both conjugate hemispheres, such that half the electrons lost are precipitated above the SIC calculation point above the city of Sapporo. These fluxes are used as an input to the SIC model, from which ionisation rates are calculated and the response of atmospheric chemistry determined.

\section{Modelling results}

4.1 Middle atmosphere response to space-based RBR precipitation

Figure 5 shows the SIC-calculated changes due to the flushing of HANE-injected electrons at all local times over 3 days, i.e., the precipitation fluxes shown in Fig. 4 and the subsequent atmospheric recovery. Here the precipitation process is assumed to start at 12:00 LT (03:00 UT), i.e., at local noon. The RBR-forced calculation is termed the "B"-run. In order to interpret the RBR-driven changes, a SIC modelling run has also been undertaken without any RBR-forcing (i.e., zero electron fluxes), termed the "C"-run, or "control". The results of this no-forcing "control" SIC-run, shown in Fig. 6, allow the calculation of "normal" conditions, and hence an indication of the significance of the changes. The top panel of Fig. 6 shows the normal diurnal variation in electron number density, the second panel shows $\mathrm{NO}_{\mathrm{x}}$ number density $\left(\mathrm{N}+\mathrm{NO}+\mathrm{NO}_{2}\right)$, the third panel $\mathrm{HO}_{\mathrm{x}}$ number density, and the lower panel shows $\mathrm{O}_{\mathrm{x}}\left(\mathrm{O}+\mathrm{O}_{3}\right)$. We use $\mathrm{NO}_{\mathrm{x}}$ and $\mathrm{O}_{\mathrm{x}}$ rather than $\mathrm{NO}$ and $\mathrm{O}_{3}$ as there are substantial diurnal variations in both the latter populations, which would lead to distracting features in the relative change plots. In all cases these panels have units of $\log _{10}\left[\mathrm{~cm}^{-3}\right]$. The atmospheric changes modelled in our study mostly occur in the mesosphere, as determined by energy spectra of the precipitating electrons. In the mesosphere changes in $\mathrm{O}_{3}$ (or $\mathrm{O}_{\mathrm{x}}$ ) are primarily caused by increases in $\mathrm{HO}_{\mathrm{x}}$, although $\mathrm{NO}_{\mathrm{x}}$ does play some role near $50 \mathrm{~km}$ and is important in $\mathrm{O}_{\mathrm{x}}$ chemistry in the upper stratosphere. Ionisation-produced $\mathrm{HO}_{\mathrm{x}}$ leads to the $\mathrm{O}_{\mathrm{x}}$ changes shown. Superimposed upon the panels of Fig. 6 is a black line indicating the solar zenith angle (plotted in degrees where $1^{\circ}=1 \mathrm{~km}$ on the altitude scale), and hence the diurnal cycle, where local midnight is shown by the highest points in the curve and the dawn/dusk transition by the horizontal black line.

The top panel of Fig. 5 shows the effect of the RBRforcing on electron number density, shown as the $\log _{10}$ of the ratio between the forced and control runs. The RBR-forcing leads to a 2-3.5 order of magnitude increase in electron number density beyond normal levels, over a wide altitude range $(\sim 40-80 \mathrm{~km})$. These very large electron number density 

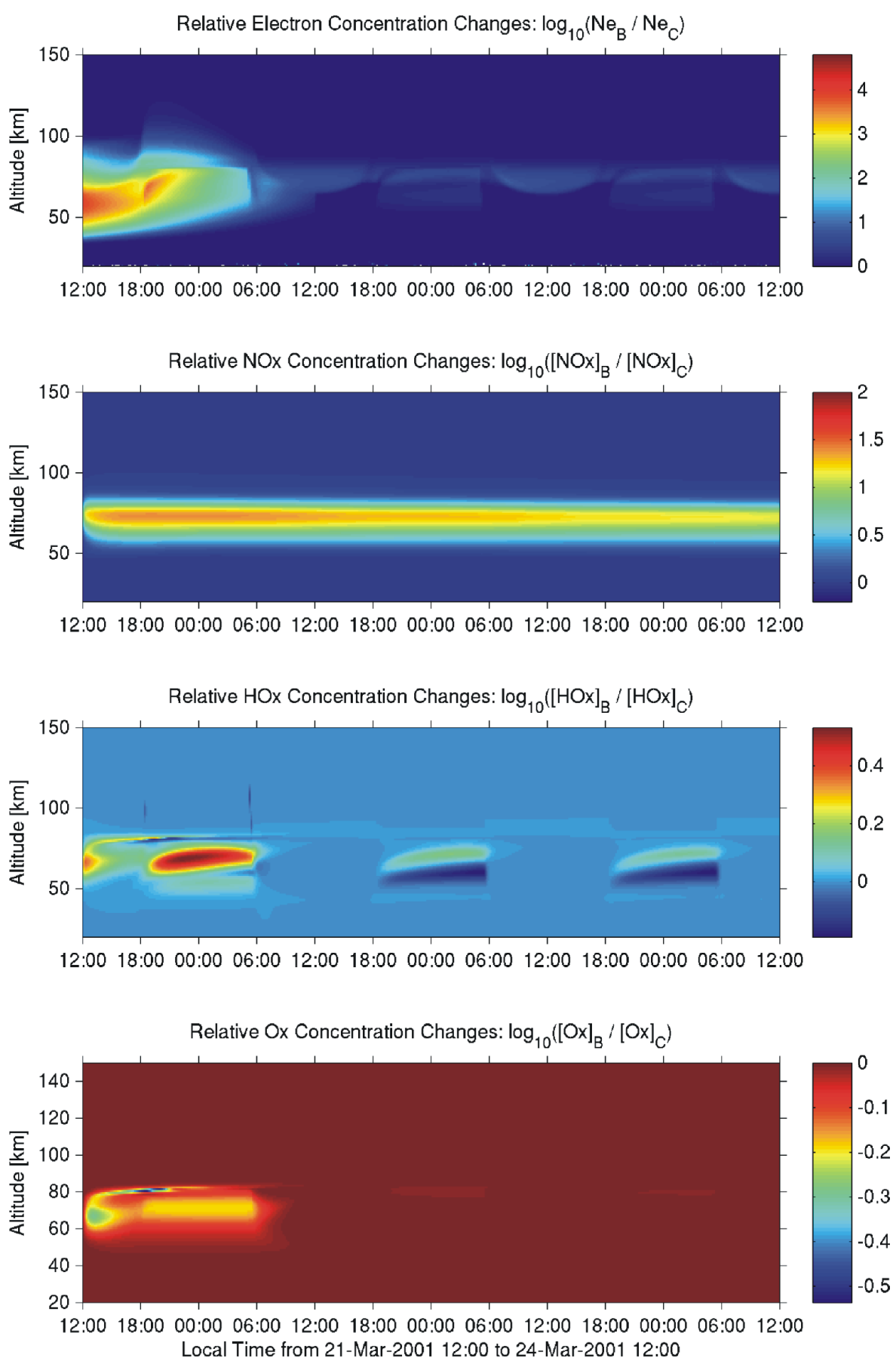

Fig. 5. The effect of the RBR-forced precipitation starting at 12 LT as calculated using the SIC model, due to the precipitating fluxes shown in Fig. 4. The top shows the RBR-forced ("B"-run) change in electron densities, relative to normal conditions ("C"-run), while the lower panels show changes in $\mathrm{NO}_{\mathrm{x}}$ and $\mathrm{O}_{\mathrm{x}}$.

changes last only as long as the RBR-forcing. However, for several days after the end of the 1 day precipitation period there are long lasting increases of about 3-10 times in the electron number density around $\sim 70-80 \mathrm{~km}$. As the relaxation time for ionisation at these altitudes is comparatively short, on the order of 10-100 s (Rodger and McCormick, Fig. 8, 2006), these long-lived changes are due to the longlived increase in $\mathrm{NO}_{\mathrm{x}}$ at $60-80-\mathrm{km}$ altitudes, as seen in the second panel of Fig. 5. Enhanced NO-levels can produce enhanced electron-levels through ionisation of the NO 

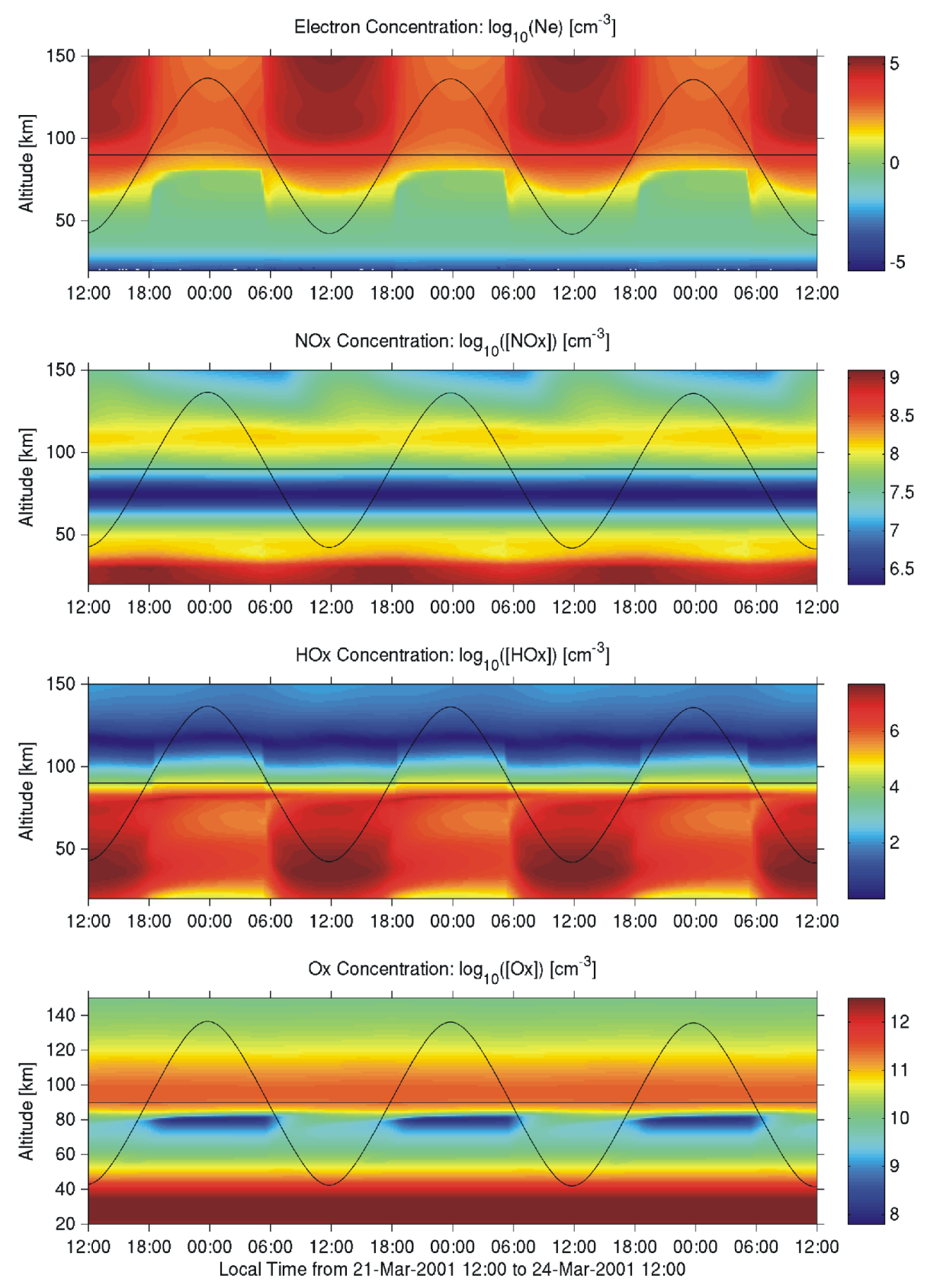

Fig. 6. The results of a SIC modelling run without any RBR-forcing (i.e., zero precipitating electron fluxes), showing the calculated "normal" conditions. Superimposed is a black curve indicating the solar zenith angle, and hence the diurnal cycle, where local midnight is shown by the highest points in the curve and the dawn/dusk transition by the horizontal black line.

by Lyman- $\alpha$ radiation, affecting the mesospheric electron density profiles in much the same way as in situ particle precipitation (e.g., Clilverd et al., $2006^{1}$ ).

The lowest panel of Fig. 5 shows the effect of the RBR-

\footnotetext{
${ }^{1}$ Clilverd, M. A., Seppälä, A, Rodger, C. J., Verronen, P. T., and Thomson, N. R.: Ionospheric evidence of thermosphere-tostratosphere descent of polar $\mathrm{NO}_{X}$, Geophys. Res. Lett., in review, 2006.
}

forced precipitation on $\mathrm{O}_{\mathrm{x}}$ relative densities. During the RBR-forcing the ozone levels decrease at $\sim 60-80 \mathrm{~km}$, by $\sim 40-50 \%$, but these decreases are significant for only about $\sim 18 \mathrm{~h}$. At dawn $(\sim 06: 00 \mathrm{LT})$ the $\mathrm{O}_{\mathrm{x}}$ recovers, as photodissociation processes are most effective, because of the high background production of $\mathrm{HO}_{\mathrm{x}}$ and the production of $\mathrm{O}_{3}$ at that time. The long-lived decrease in nighttime $\mathrm{O}_{\mathrm{x}}$ is relatively small, at the $\sim-10 \%$ level. 

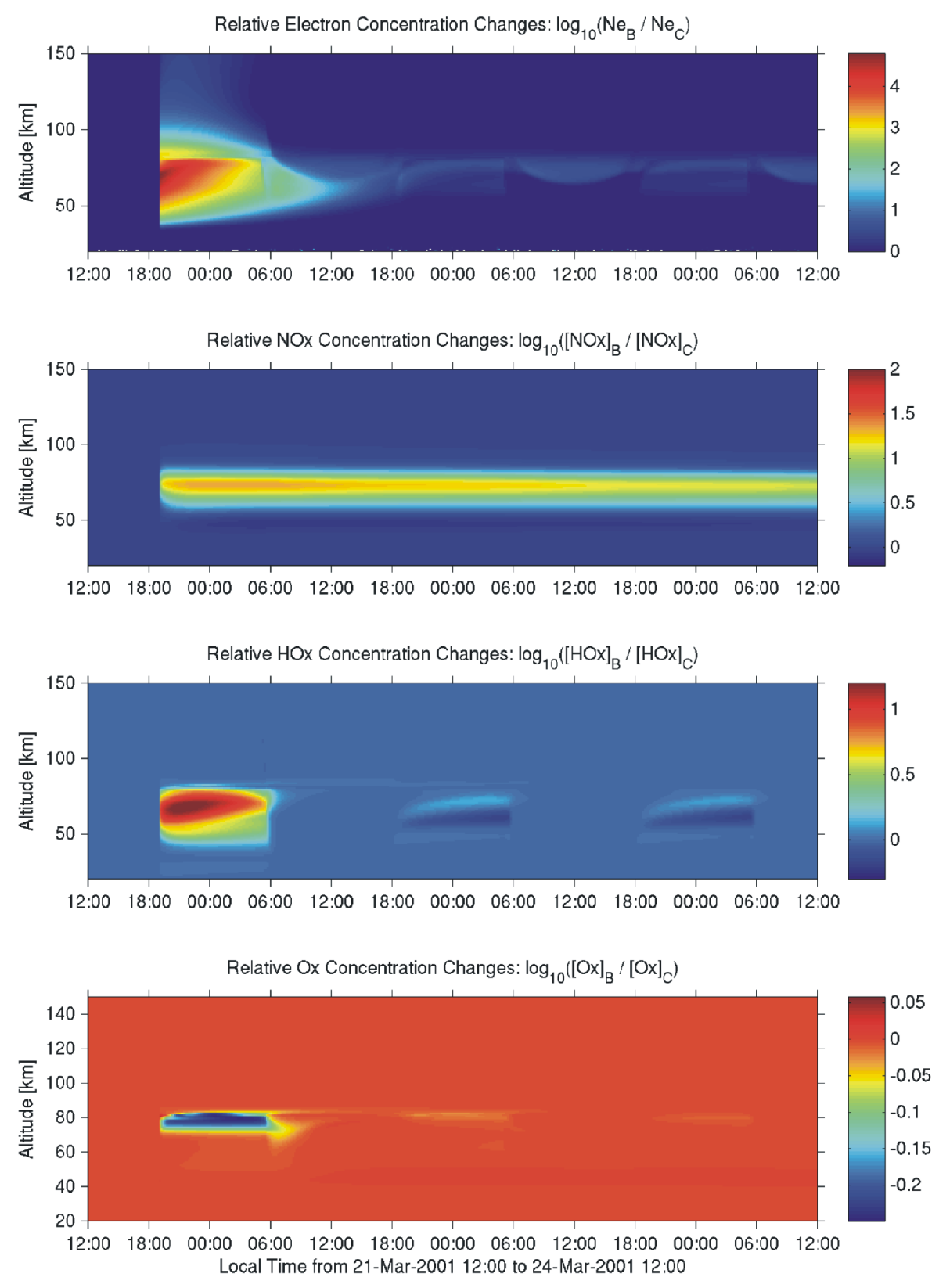

Fig. 7. The effect of the RBR-forced precipitation starting at 19 LT, to be contrasted with Fig. 5.

The lifetime of odd nitrogen (NO) is strongly decreased by sunlight, and hence the precipitation might be expected to have a much less significant effect if the largest fluxes occur in sunlit locations. In order to test this we repeated the SIC calculations described above for an RBR-forcing start at 19:00 LT, i.e. around sunset. Figure 7 shows the changes in electron number density, $\mathrm{NO}_{\mathrm{x}}, \mathrm{HO}_{\mathrm{x}}$, and $\mathrm{O}_{\mathrm{x}}$, to be contrasted with Fig. 5. While there are some small differences between the timing and evolution of the mesospheric changes shown in these two figures, the altitudes and magnitudes of the changes are rather similar. There is not a strong depen- dence on the RBR-forcing start times in LT, and as such the conclusions we draw from our calculations above Sapporo should apply equally well for all the locations on this L-shell into which RBR-produced precipitation will be driven.

Figure 8 considers the case for a 10-day operation time. While the same amount of "total" injected flux is precipitated in this case as in the 1-day case, it is spread out over considerably more in time, and hence with smaller peak fluxes. However, this does not necessarily lead to smaller mesospheric changes in its longitude sector. Figure 8 shows the SIC calculated mesospheric changes for the case where the 

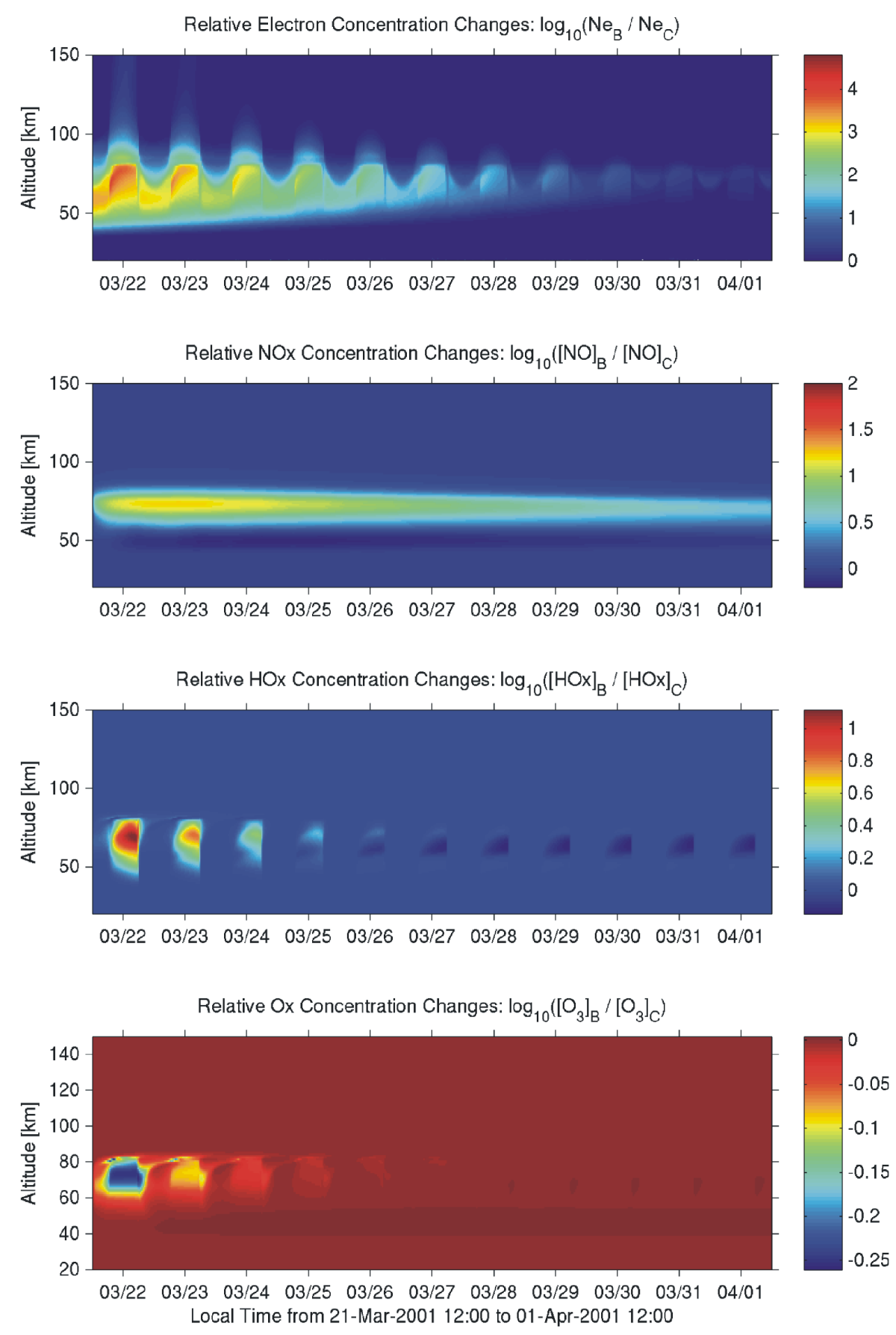

Fig. 8. The effect of the RBR-forced precipitation starting at 12 LT, in the same format as Fig. 7. In this case the RBR-system is assumed to flush the HANE-injected electrons into the upper atmosphere over 10 days.

RBR-system flushes the HANE-injected electrons into the upper atmosphere over the longer time scale of 10 days, starting at 12:00 LT on day 1. Otherwise the format of this plot is identical to Fig. 7. The peak magnitudes in the RBR enhancements to $\mathrm{NO}_{\mathrm{x}}$ and $\mathrm{HO}_{\mathrm{x}}$ leading to depletions in $\mathrm{O}_{\mathrm{x}}$, are much the same as the previous cases, the primary difference being that some effect lingers in $\mathrm{O}_{\mathrm{x}}$ depletion for 4-5 days after the RBR-system begins operations. RBR-driven changes in electron density persist for $\sim 8$ days, after which the remaining electron density increases resemble the longlived NO produced change seen in Fig. 5 and 7.

The RBR-forced neutral chemistry changes seen in Figs. 5, 7 and 8 are significant during the timescale of the precipitation, but are generally not long-lasting. The magnitude, 

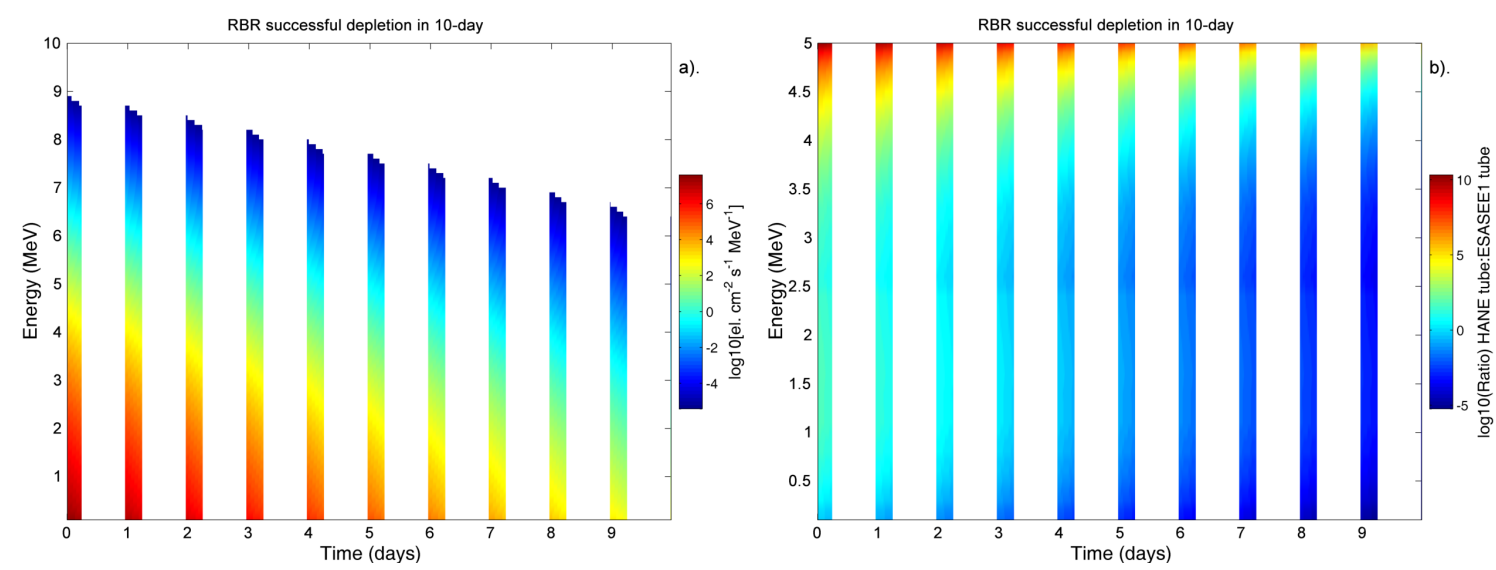

Fig. 9. The changing HANE-injected differential flux at $L=1.57$ during the operation of an assumed ground based RBR-system, in the same format as Fig. 4.

time-scales, and altitudes of these changes are rather similar to the $\mathrm{NO}_{\mathrm{x}} / \mathrm{HO}_{\mathrm{x}}$ enhancements and $\mathrm{O}_{3}$ depletions calculated by the SIC model for large solar proton events (Verronen et al., 2002, 2005), confirmed by experimental observations using the GOMOS satellite-bourn instrument (Seppälä et al., 2005; Verronen et al., 2005) and subionospheric VLF propagation measurements (Clilverd et al., 2005, 2006). Thus while RBR-forced precipitation should be expected to be a rare occurrence, even if it was used to mitigate the effects of intense natural injections while providing a defence against possible HANE-injections, the effects are no more significant than large solar proton events. Solar protons entering the Earth's magnetosphere are guided by the Earth's magnetic field and precipitate into the polar cap areas (Rodger et al., 2006). Solar proton events can therefore produce NO increases inside the polar vortex during the Antarctic winter, when the low levels of solar illumination lead to long-lived NO enhancements and hence significant depletions of middle atmospheric ozone. In contrast, the RBR-forced precipitation will occur at low- to mid-latitudes and is unlikely to reach polar latitudes, such that the large NO enhancements will generally have short lifetimes. Even in the extreme RBR-system considered here, our calculations indicate that the effects on the neutral constituents of the middle atmosphere will be less than that which occur in the polar regions during large solar proton events.

\subsection{Contrast with ground-based RBR-system}

Publications discussing a practical space-based RBR-system have in part been triggered by the suggestion that existing manmade very low frequency (VLF) communications transmitters on the Earth's surface may drive the most significant losses from the inner radiation belts (Abel and Thorne, 1998; 1999). Such discussions tend to refer to ground-based transmitters acting to test the feasibility of possible spacebased systems (e.g., Dupont, 2004). However, one might also envisage a deployed RBR-system using ground-based VLF transmitters. In order to estimate the possible effect of a ground-based system, we again take the extreme situation, in this case a single RBR-transmitter. We assume that this system can successfully flush the HANE-injected electrons into the upper atmosphere over 10 days. Experimental observations of electron precipitation due to wave-particle interactions from ground-based VLF transmitters have shown that the interactions are likely to be effective for only $\sim 7 \mathrm{~h}$ per day (23:00-06:00 LT, i.e., local nighttime) over $30^{\circ}$ in longitude centred on the transmitter longitude (Datlowe et al., 1995), unlike the case for a system of space based transmitters (which we earlier assumed were regularly spaced). The variation in effective power of a ground-based transmitter has been estimated to have an exponential drop-off with longitude with $15^{\circ}$ folding distance, so that the average wave power is 0.63 of the maximum (Abel and Thorne, 1998). In order to flush all the HANE-injection electrons over 10 days, the precipitation fluxes around the transmitter will be higher than in the space-based case, due to the spatial and LT limits. Figure 9 shows how the differential omnidirectional trapped flux at $L=1.57$ caused by the HANE will change with our assumed ground-based RBR-system driving a depletion over 10 days, but is otherwise in the same format as Fig. 4.

The SIC calculated mesospheric changes due to this precipitation are shown in Fig. 10, again in the same format as Fig. 5. Again a 12:00 LT RBR-start is taken, with the groundbased RBR transmitter assumed to be located at the same longitude as Sapporo, our calculation point. While the electron density changes in Fig. 10 are of similar magnitudes to those shown in Figs. 6 and 7, the long-lasting RBR-driven precipitation produces larger $\mathrm{NO}_{\mathrm{x}}$ enhancements (by a factor of $\sim 5$ ) and also deeper $\mathrm{O}_{\mathrm{x}}$ depletions (depletions down to $\sim 25 \%$ of control). This is as the time-integrated energy deposited by electron precipitation is not the same between the two cases, as in the ground-based transmitter case the 

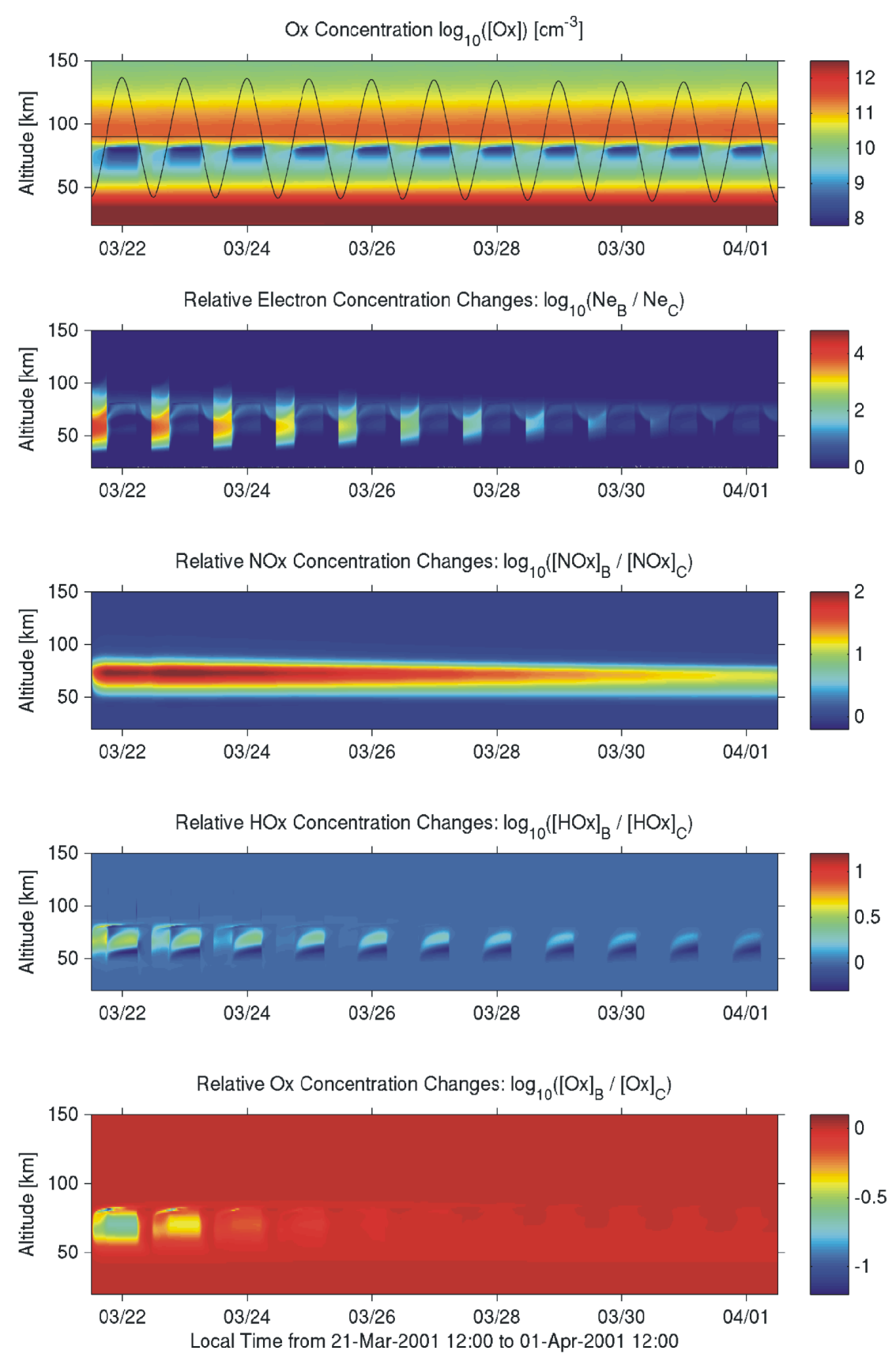

Fig. 10. The effect of the precipitation driven by a single station ground based RBR system-forced. The format is as shown in Fig. 5 driven by the precipitation fluxes shown in Fig. 9.

electron precipitation is confined in longitude. While this effect is somewhat larger than that shown in the earlier cases, it is still within the expected effects of large solar proton events. The magnitude, duration and altitude range of the initial $\mathrm{O}_{\mathrm{x}}$ depletion is similar to that calculated for the 29,500 proton flux unit event of 29 October 2003 (Verronen et al., Fig. 3, 2005). The $\mathrm{O}_{\mathrm{x}}$ depletions become progressively less significant for each day of RBR-operation, lasting perhaps $\sim 4-5$ days of the 10-day operational period assumed.
The operation of the RBR produces excess ionisation at mid- or even low-latitudes, producing temporary neutral atmospheric changes on scales observable by experiments that probe atmospheric composition (e.g., GOMOS). Thus significant disruption to the normal atmospheric properties would be expected to occur at a level that is probably exceptional at these latitudes, but is comparable to the changes forced at high latitudes by highly energetic solar proton events. 


\section{Effect on HF communication}

It is well known that the additional ionisation produced by solar flares can lead to "Shortwave fadeouts", also known as "HF blackouts", where high frequency (HF) radio waves (3-30 MHz) suffer from increased attenuation caused by absorption in the ionospheric D-region (Davies, 1990). For the case of solar flares, the HF radio blackout will primarily affect the sunlit sector of the Earth, stopping radio contact with mariners and en-route airplanes (Jones et al., 2005). According to NOAA's Space Environment Center, for severe cases, corresponding to peak $\mathrm{X}$-ray fluxes in the $0.1-8 \mathrm{~nm}$ range $>10^{-3} \mathrm{Wm}^{-2}$ (i.e., $>\mathrm{X} 10$ ), satellite based navigation systems may also suffer increased errors. As these solar flare produced disruptions are caused by additional ionisation in the D-region, the precipitation driven by the RBR-system might also lead to similar disruptions. Unlike the solar flare case, where the effect is limited to the sunlit sector of the Earth, the disruptions cased by the RBR-system could affect both the sunlit and night sectors of the Earth.

In order to estimate the HF attenuation levels, we consider the variation with time of the Highest Affected Frequency (HAF) during the RBR-forced precipitation. The HAF is defined as the frequency which suffers a loss of $1 \mathrm{~dB}$ during vertical propagation from the ground, through the ionosphere, and back to ground. Radio frequencies lower than the HAF suffer an even greater loss. According to the D Region Absorption Documentation provided by the NOAA Space Environment Center (http://www.sec.noaa. gov/rt_plots/dregionDoc.html) and based on the Space Environmental Forecaster Operations Manual (1997), the empirically derived relationship between HAF and solar $0.1-0.8 \mathrm{~nm}$ $\mathrm{X}$-ray flux is:

$\mathrm{HAF}=10 \times \log _{10}($ flux $)+65$,

where $\mathrm{HAF}$ is given in $\mathrm{MHz}$ and the $\mathrm{X}$-ray flux is in units of $\mathrm{W} \mathrm{m}^{-2}$. As an example, an X20 flare, which has peak $0.1-0.8 \mathrm{~nm}$ X-ray fluxes of $2.0 \mathrm{~mW} \mathrm{~m}^{-2}$, produces a HAF of $38 \mathrm{MHz}$. Flares of this magnitude lead to "extreme" Radio Blackouts, with essentially no HF radio contact with mariners or en-route aviators, and increased satellite navigation errors. NOAA has defined a Space Weather Scale for Radio Blackouts (Poppe, 2000), ranging from R1 describing a minor disruption due to an M1 flare $\left(10 \mu \mathrm{W} \mathrm{m}^{-2}\right.$ peak $0.1-0.8 \mathrm{~nm}$ X-ray flux) to R5 for the extreme blackout case described above. We will employ this scale to provide an indication of the severity of the RBR-induced blackouts.

The response of the ionospheric D-region electron density to solar flares has been studied by use of subionospheric VLF propagation (e.g., Thomson et al., 2004; 2005). This work has shown that the electron density responds in a consistent way, providing a link between the electron density changes and X-ray fluxes. These authors characterise the $\mathrm{D}$ region through a Wait ionosphere defined by just two parameters, the "reflection height" $H^{\prime}$, in kilometres, and the exponential sharpness factor, $\beta$, in $\mathrm{km}^{-1}$ (Wait and Spies, 1964), using the relationship:

$$
\begin{aligned}
N_{e}(z) & =1.43 \times 10^{13} \exp \left(-0.15 h^{\prime}\right) \\
& \times \exp \left((\beta-0.15)\left(z-h^{\prime}\right)\right)\left[\mathrm{el} . \mathrm{m}^{-3}\right] .
\end{aligned}
$$

Figure 9 of Thomson et al. (2005) provides plots of the values of $\beta$ and $H^{\prime}$ required to reproduce experimentally observed absolute amplitude and phase changes driven by peak solar flare X-ray fluxes.

By fitting Wait ionosphere $\beta$ and $H^{\prime}$ parameters to the SIC calculated electron densities we have used Fig. 9b of Thomson et al. (2005) to estimate the equivalent X-ray fluxes, and hence determine the HAF likely due to the increased ionization produced by the RBR-forced precipitation. Note that the observations of Thomson et al. (2005) suggest that there is little measurable change in ionospheric D-region electron densities for $0.1-0.8 \mathrm{~nm}$ X-ray flux less than $\sim 1.5 \mu \mathrm{W} \mathrm{m}^{-2}$, at least for observations based on subionospheric VLF propagation. In these cases, which correspond to very minor ionospheric disturbances (or undisturbed conditions), the HAF has been set to zero.

The HF blackout estimates for the 1-day space based RBR case (Fig. 5) are shown in Fig. 11. The upper panel indicates the change in the Wait ionosphere $H^{\prime}$ parameter. The heavy line represents the RBR case, while the light dotted line represents the unforced case taken from the control runs. At the start of the RBR forcing (12 LT) there is a very large change in $H^{\prime}$ when compared with the undisturbed situation. The large difference between the forced and unforced $H$ ' values lasts until dawn on the second day, when the variation in $H^{\prime}$ shifts into a new, but stable, regime because of the increased $\mathrm{NO}_{\mathrm{x}}$. This is consistent with the behaviour of the electron density seen in Fig. 5. The middle panel of Fig. 11 shows the equivalent peak X-ray power in the $0.1-0.8 \mathrm{~nm}$ wavelength range which would cause the same $H^{\prime}$ value during a solar flare, as determined from Fig. 9 of Thomson et al. (2005). There is a very large change in equivalent peak $\mathrm{X}$-ray power over the first $12 \mathrm{~h}$, representing the time period when the RBR-forced changes to the electron density are the most significant. The lower panel of this figure presents the Highest Affected Frequency calculated using Eq. (4) from the equivalent peak X-ray power shown in the middle panel. The NOAA Radio Blackout Scale has been added for comparison. At the start of the RBR-forcing the HF blackout level is at "Extreme" levels equivalent to the effects of a X20 solar flare (or larger). Such events are very rare, on average less than once per 11-year solar cycle. Over the course of $\sim 6 \mathrm{~h}$ the HF blackout level drops from "Extreme" to "Severe", which occurs on average about 8 times per solar cycle. The HAF then rapidly decreases to be "Minor" about 9-10 h after the start of the RBR-forcing. The operation of an RBRsystem would clearly lead to unusually intense HF blackouts for $\sim 9 \mathrm{~h}$, producing large scale disruptions to radio communication and navigation systems. 

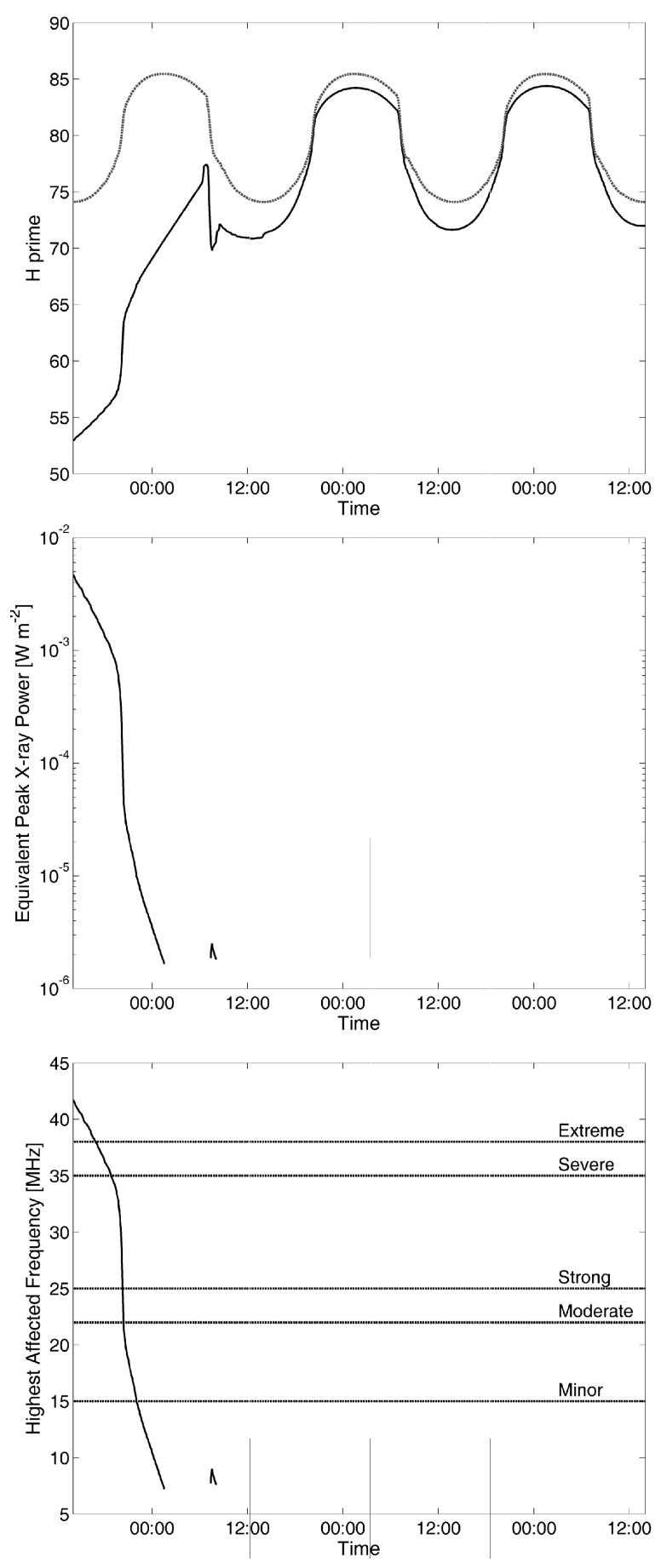

Fig. 11. Estimate of the severity of the RBR-forced HF blackout for the case shown in Fig. 5. The upper panel indicates the change in the Wait ionosphere $H^{\prime}$ parameter for the forced (heavy line) and unforced (light line) cases. The middle panel shows the equivalent peak X-ray power in the $0.1-0.8 \mathrm{~nm}$ range which would cause the same $H^{\prime}$ during a solar flare. The lower panel is the Highest Affected Frequency calculated from the equivalent peak X-ray power. The NOAA Radio Blackout Scale has been added for comparison.

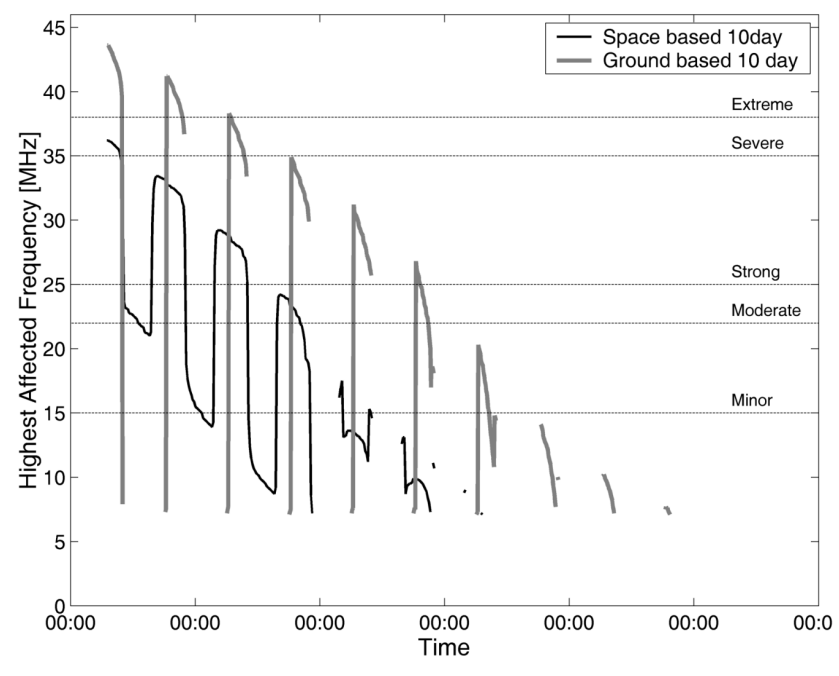

Fig. 12. The Highest Affected Frequency for the RBR-cases shown in Figs. 8 and 9, in the same format as the lower panel in Fig. 11.

While the system would produce an unusually intense HF blackout, our modelling indicates that the changes in $\mathrm{O}_{\mathrm{x}}$ levels would be well within those caused by natural forcing, and that both changes would be short-lived. In the extreme, and hopefully unlikely case of a HANE, the disruption caused during RBR operation would probably be viewed as acceptable. However, this might not be the case for an RBRoperating to flush an intense natural injection, although is clearly a societal rather than a scientific matter. We therefore consider whether a longer operational time would lead to smaller levels of HF blackout. Figure 12 examines the HF absorption effects caused by an RBR-system operating over a 10-day timescale, either space based (Fig. 8) or ground based (Fig. 10). In the case of the space-based RBR, the HF blackout levels are smaller than the 1-day case presented in Fig. 11 above, but remain above "Strong" for parts of several days. It appears that an RBR-system operating over a longer time scale would be more disruptive than a system which can operate very rapidly. While a ground-based system produces more short-lived changes to HF blackout levels, due to the limitation to nighttime operation, the peak HF absorption levels are greater than that for a 10-day space-based operation, producing "Moderate" to "Extreme" HF blackout conditions for parts of 6-7 days. Again, it seems likely that any of these system configurations would be acceptable for the extreme case of a high-altitude nuclear explosion, but possibly not for mitigating the effects of an intense natural injection. It appears that HF blackout effects may be the most significant disruptions which would be caused by the operation of an RBR-system. 


\section{HANE injections at different locations}

What if the HANE was at a different location than that of Starfish Prime? Most of the publications which discuss the threat posed by HANE "pumping-up" the radiation belts mention different locations with differing geomagnetic latitudes. In addition, nuclear-tipped anti-ballistic missile defence systems are currently operational around Moscow and were also briefly deployed in the United States. These systems are designed to destroy incoming warheads by a nuclear explosion at altitudes $>100 \mathrm{~km}$, and could also lead to a HANE-injection into the radiation belts, as an unintended consequence of protecting the target. On the basis of Starfish Prime, we argue that HANE occurring at $L<1.25$ will produce equilibrium-fission spectra for $L<1.25$ and softer spectra at higher L-shells, in a similar way to Starfish Prime. Such a HANE will be rather similar to that from Starfish Prime, and any RBR-mitigation efforts will be well represented by the calculations presented in this study. HANE occurring at higher L-shells will move the hard-spectra trapped flux to higher L-shells. On the basis of the conclusions drawn in Fig. 4, we argue that the harder spectra will, if flushed by an RBR-system, produce effects much like a solar proton event with a very hard spectrum. On 20 January 2005 an extremely energetic solar proton event occurred: the flux of extremely high energy solar protons ( $>100 \mathrm{MeV}$ from GOES) was of the same order as in the well known October 1989 SPE (e.g. Reid et al., 1991; Jackman et al., 1995), whilst the lower energy fluxes remained at moderate levels $(>10 \mathrm{MeV}$ proton flux peak $1860 \mathrm{pfu}$ while the $>100 \mathrm{MeV}$ protons peaked at $652 \mathrm{pfu}$ ). However, a study of this extreme solar proton event using the SIC model indicated that there was little additional ozone loss at stratospheric altitudes, even though a significant population of protons would reach these altitudes at these high-latitudes and cause in-situ changes (Seppälä et al., 2006). Ozone loss in the stratosphere is determined by cycles of $\mathrm{NO}_{\mathrm{x}}, \mathrm{Cl}_{\mathrm{x}}, \mathrm{Br}_{\mathrm{x}}$, and $\mathrm{HO}_{\mathrm{x}}$ depending on the altitude region. SPE-induced changes in the stratosphere are due to an increase in $\mathrm{NO}_{\mathrm{x}}$. However, the modelling concluded that the SPE-forced $\mathrm{NO}_{\mathrm{x}}$ production even in this very hard event is not significant in the middle and lower stratosphere when contrasted with the typical $\mathrm{NO}_{\mathrm{x}}$ population. It appears, therefore, that the calculations presented in our study should generally be representative of a variety of different HANE and RBR locations. One possible mechanism by which a high-latitude HANE followed by RBR operation could lead to stratospheric $\mathrm{O}_{3}$ changes, involves strong downward transport due to the polar vortex. During the polar winter odd nitrogen produced by energetic particle precipitation can survive, and in the presence of strong polar vortex conditions, descend into the stratosphere (Solomon et al., 1982; Siskind, 2000). During the northern polar winter of 2003-2004 these conditions existed; Randall et al. (2005) reported unprecedented levels of spring-time stratospheric $\mathrm{NO}_{\mathrm{x}}$ as a result. However, in general both significant intense precipitation fluxes and a strong polar vortex are needed to transport odd nitrogen to stratospheric altitudes (Clilverd et al., $2006^{2}$ ). In the case of a high-latitude HANE, the RBR operation would fill the role of the geomagnetic storm producing intense precipitation fluxes, while a strong polar vortex would still be necessary to transport $\mathrm{NO}_{\mathrm{x}}$ to lower altitudes.

\section{Summary}

High altitude nuclear explosions (HANEs) can produce large scale injections of relativistic particles into the inner radiation belts. In some cases, geomagnetic storms are also associated with increases in the inner belt relativistic electron population. It is recognised that these large increases in $>1 \mathrm{MeV}$ trapped electron fluxes would shorten the operational lifetime of Low Earth Orbiting satellites, threatening a large population of valuable satellites. Due to the lifetime of the injected electrons, any manned spaceflights would also need to be delayed for a year or more. Therefore, studies are being undertaken to bring about practical human control of the radiation belts to protect Earth-orbiting systems from natural and manmade injections of relativistic electrons, termed "Radiation Belt Remediation" (RBR). In this paper we have examined the upper atmospheric consequences of an RBR system in operation.

In order to estimate the significance of RBR-driven precipitation to the upper atmosphere, we considered an RBRsystem operating to flush the artificial radiation belt injected by a Starfish Prime-type HANE over either 1 or 10 days, assuming a space-based system operating over all local times. For the longer operation time we also considered a ground-based RBR system. The RBR-forced neutral chemistry changes, leading to $\mathrm{NO}_{\mathrm{x}}$ enhancements and $\mathrm{O}_{\mathrm{x}}$ depletions, are significant during the timescale of the precipitation, but are generally not long-lasting. The magnitude, time-scales, and altitudes of these changes are rather similar to the $\mathrm{NO}_{\mathrm{x}}$ enhancements and $\mathrm{O}_{3}$ depletions calculated by the SIC model for large solar proton events (Verronen et al., 2002, 2005). Thus while RBR-forced precipitation should be expected to be a rare occurrence, even if it was used to mitigate the effects of intense natural injections while providing a defence against possible HANE-injections, the effects are no more significant than large solar proton events. The primary difference between the RBR-forced changes and those driven by solar proton events is that the RBR-forced precipitation will occur at low- to mid-latitudes and are unlikely to reach polar latitudes. However, in this case the large $\mathrm{NO}_{\mathrm{x}}$ and $\mathrm{HO}_{\mathrm{x}}$ enhancements will generally have short lifetimes, such that even for a fairly extreme case of RBR-system operation, and the significance to $\mathrm{O}_{3}$ levels will be less than that

\footnotetext{
${ }^{2}$ Clilverd, M. A., A. Seppälä, Rodger, C. J., Thomson, N. R., and Lichtenberger, J.: Temporal variability of the descent of highaltitude $\mathrm{NO}_{X}$, J. Geophys. Res., in preparation, 2006.
} 
which occurs in the polar regions during large solar proton events.

In contrast, RBR-operation will lead to unusually intense HF blackouts for about the first half of its operation time, producing large scale disruptions to radio communication and navigation systems. Both space-based and ground-based RBR systems would create HF disruptions, although the duration and local time of the effect is dependent on the system case. It is not clear that an RBR-system operating over 10 days would produce lower levels of HF disruption than if operated over 1 day. While the neutral atmosphere changes are not particularly important, HF disruptions could be an important area for policy makers to consider, particularly for the remediation of natural injections.

Acknowledgements. C. J. Rodger would like to thank B. Tustin of Dunedin for her support. We are grateful to the NSSDC at GSFC for providing reports on radiation belt models, and A. Vampola for his advice concerning the ESA-SEE1 model.

Topical Editor I. A. Daglis thanks two referees for their help in evaluating this paper.

\section{References}

Abel, B. and Thorne, R. M.: Electron scattering loss in earth's inner magnetosphere-1. Dominant physical processes, J. Geophys. Res., 103, 2385-2396, 1998.

Abel, B. and Thorne, R. M.: Correction to "Electron scattering loss in earth's inner magnetosphere, 1. Dominant physical processes" and "Electron scattering loss in earth's inner magnetosphere, 2. Sensitivity to model parameters" by Abel, B. and Thorne, R. M., J. Geophys. Res., 104, 4627-4628, 1999.

Baker, D. N., Kanekal, S. G., Li, X., Monk, S. P., Goldstein, J., and Burch, J. L.: An extreme distortion of the Van Allen belt arising from the "Halloween" solar storm in 2003, Nature, 432(7019), 878-880, 2004.

Banks, P. M. and Kockarts, G.: Aeronomy, vol. B, chap. 15, Academic Press, 1973.

Brasseur, G. and Solomon, S.: Aeronomy of the Middle Atmosphere, second edition, D. Reidel Publishing Company, Dordrecht, 1986.

Carter, R. E., Reiner, F., Wagner, J. J., and Wyman, M. E.: Free antineutrino absorption cross section, 2, Expected cross section from measurements of fission fragment electron spectrum, Phys. Rev., 113, 280-286, 1959.

Chabrillat, S., Kockarts, G., Fonteyn, D., and Brasseur, G.: Impact of molecular diffusion on the $\mathrm{CO}_{2}$ distribution and the temperature in the mesosphere, Geophys. Res. Lett., 29, 1-4, 2002.

Clilverd, M. A., Rodger, C. J., Ulich, Th., Seppälä, A., Turunen, E., Botman, A., and Thomson, N. R.: Modelling a large solar proton event in the southern polar cap, J. Geophys. Res., 110(A9), doi:10.1029/2004JA010922, 2005.

Clilverd, M. A., Seppälä, A, Rodger, C. J., Thomson, N. R., Verronen, P. T., Turunen, E., Ulich, Th., Lichtenberger, J., and Steinbach, P.: Modelling the ionospheric effects of solar proton events in the polar atmosphere, Radio Sci., 41(2), RS2001, doi:10.1029/2005RS003290, 2006.
Datlowe, D. W., Imhof, W. L., Fishman, G. J., and Finger, M. H.: Local time and seasonal variations in the precipitation of energetic electrons from the inner radiation belt by cyclotron resonance with waves from powerful VLF transmitters, Radio Sci., 30(1), 47-56, 1995.

Davies, K.: Ionospheric radio, Peter Peregrinus, London, 1990.

Dupont, D. G.: Nuclear explosions in orbit, Scientific American, 68-75, 2004.

Hedin, A. E.: Extension of the MSIS Thermospheric model into the middle and lower Atmosphere, J. Geophys. Res., 96, 1159-1172, 1991.

Hess, W. N.: The artificial radiation belt made on July 9, 1962, J. Geophys. Res., 68(3), 667-683, 1963.

Hess, W. N.: The radiation belt and magnetosphere, Blaisdell Pub. London, 1968.

Jackman, C. H., Cerniglia, M. C., Nielsen, J. E., Allen, D. J., Zawodny, J. M., McPeters, R. D., Douglass, A. R., Rosenfield, J. E., and Hood, R. B.: Two-dimensional and three-dimensional model simulations, measurements, and interpretation of the October 1989 solar proton events on the middle atmosphere, J. Geophys. Res., 100, 11 641-11 660, 1995.

Jones, J. B. L., Bentley, R. D., Hunter, R., Iles, R. H. A., Taylor, G. C. and Thomas, D. J.: Space weather and commercial airlines, Adv. Space Res., 36(12), 2258-2267, 2005.

Inan U. S., Bell, T. F., Bortnik, J., and Albert, J. M.: Controlled precipitation of radiation belt electrons, J. Geophys. Res., 108, 1186, doi:10.1029/2002JA009580, 2003.

Li, X. L. and Temerin, M. A.: The electron radiation belt, Space Sci. Rev., 95(1-2), 569-580, 2001.

MacNamara, L. F.: High frequency radio propagation, in: Handbook of Geophysics and the Space Environment, edited by: Jursa, A. S., Chapter 10, Air Force Geophys. Lab., U.S. Air Force, 45-65, 1985.

Massey, H.: Space Physics, Cambridge University Press, 1964.

Papadopoulos, D.: Threat to satellites of a high altitude nuclear detonation, Presentation at future of space: 1st Meeting of scientific panel, The Eisenhower Institute, Washington, D.C., 11 December 2001 (available from http://www.eisenhowerinstitute.org/programs/ globalpartnerships/fos/newfrontier/articles-papers.htm), 2001.

Parmentola, J.: High altitude nuclear detonations (HAND) against low earth orbit satellites ("HALEOS"), Report of the Defense Threat Reduction Agency, Advanced Systems and Concepts Office, Fort Belvoir, Virginia, April 2001. (available from http: //www.fas.org/spp/military/program/asat/haleos.pdf), 2001.

Poppe, B.: New Scales Help Public, Technicians Understand Space Weather, Eos Trans., Vol. 81 (29), 322, 2000.

Randall, C. E., Harvey, V. L., Manney, G. L., Orsolini, Y., Codrescu, M., Sioris, C., Brohede, S., Haley, C. S., Gordley, L. L., Zawodny, and Russell, J. M.: Stratospheric effects of energetic particle precipitation in 2003-2004, Geophys. Res. Lett., 32, L05802, doi:10.1029/2004GL022003, 2005.

Rees, M. H.: Physics and chemistry of the upper atmosphere, Cambridge University Press, Cambridge, 1989.

Reeves, G. D., McAdams, K. L. Friedel, R. H. W., and O’Brien, T. P.: Acceleration and loss of relativistic electrons during geomagnetic storms, Geophys. Res. Lett, 30(10), 1529, doi:10.1029/2002GL016513, 2003.

Reid, G. C., Solomon, S., and Garcia, R. R.: Response of the mid- 
dle atmosphere to the solar proton events of August-December, 1989, Geophys. Res. Lett., 18, 1019-1022, 1991.

Rishbeth, J. W. and Gariott, O. K.: Introduction to Ionospheric Physics, New York, Academic, 1969.

Rodger, C. J., Clilverd, M. A., and McCormick, R. J.: Significance of lightning generated whistlers to inner radiation belt electron lifetimes, J. Geophys. Res., 108(12), 1462, doi:10.1029/2003JA009906, 2003.

Rodger, C. J., Clilverd, M. A., Verronen, P. T., Ulich, Th., Jarvis, M. J., and Turunen, E.: Dynamic geomagnetic rigidity cutoff variations during a solar proton event, J. Geophys. Res., J. Geophys. Res., 111, A04222, doi:10.1029/2005JA011395, 2006.

Rodger, C. J. and McCormick, R. J.: Remote sensing of the upper atmosphere by VLF, in: Sprites, Elves and Intense Lightning Discharges: Proceedings of the NATO Advanced Study Institute from 21-30 July 2004, edited by: Füllekrug, M., Nato Science Series II (Mathematics, Physics and Chemistry), Vol. 225, Springer, ISBN 1-4020-4627-8, 2006.

Satellite Industry Association: Satellite Industry Overview, presentation to the U.S. Department of Commerce, 16 December 2004. (http://www.sia.org/industry_overview/sat101.pdf), 2004.

Seppälä, A., Verronen, P. T., Kyrölä, E., Hassinen, S., Backman, L., Hauchecorne, A., Bertaux, J. L., and Fussen, D.: Solar proton events of October-November 2003: Ozone depletion in the Northern hemisphere polar winter as seen by GOMOS/Envisat, Geophys. Res. Lett., 31(19), L19, 107, doi:10.1029/2004GL021042, 2004.

Seppälä, A., Verronen, P. T., Sofieva, V. F., Tamminen, J., Kyrölä, E., Rodger, C. J., and Clilverd, M. A.: Destruction of the tertiary ozone maximum during a solar proton event, Geophys. Res. Lett., 33, L07804, doi:10.1029/2005GL025571, 2006.

Shimazaki, T.: Minor Constituents in the Middle Atmosphere (Developments in Earth and Planetary Physics), No 6, D. Reidel Publishing Co., Dordrecht, Netherlands, 1984.

Siskind, D. E: On the coupling between the middle and upper atmospheric odd nitrogen, in Atmospheric science across the stratopause, Geophysical Monograph, 123, 101-116, 2000.

Solomon S, Crutzen, P. J., and Roble, R. G.: Photochemical coupling between the thermosphere and the lower atmosphere, 1 ., Odd nitrogen from 50 to $120 \mathrm{~km}$, J. Geophys. Res., 87, 72067220, 1982a.

Space Environmental Forecaster Operations Manual, page 4.3.1, 55th Space Weather Squadron, Falcon AFB, USAF, 21 October 1997, as referenced by the NOAA Space Environment Center at http://www.sec.noaa.gov/rt_plots/dregionDoc.html, 1997.

Steer, I.: Briefing: High-altitude nuclear explosions; Blind, deaf and dumb, Janes Defense Weekly, 20-23, 2002.

Teague, M. and Vette: The inner zone electron model AE-5, National Space Science Data Center, Rep. NSSDC 72-10, Greenbelt, Md., 1972.

Thomas, L. and Bowman, M. R.: A study of pre-sunrise changes in negative ions and electrons in the D-region, Ann. Geophys., 4, 219-228, 1986.

Thomson, N. R., Rodger, C. J., and Dowden, R. L.: Ionosphere gives size of greatest solar flare, Geophys. Res. Lett., 31(6), L06803, doi:10.1029/2003GL019345, 2004.
Thomson, N. R., Rodger, C. J., and Clilverd, M. A.: Large solar flares and the ionospheric D-region enhancements, J. Geophys. Res., 110, A06306, doi:10.1029/2005JA011008, 2005.

Tobiska, W. K., Woods, T., Eparvier, F., Viereck, R., Floyd, L. D. B., Rottman, G., and White, O. R.: The SOLAR2000 empirical solar irradiance model and forecast tool, J. Atmos. Terr. Phys., 62, 1233-1250, 2000

Turunen, E., Matveinen, H., Tolvanen, J., and Ranta, H.: D-region ion chemistry model, in: STEP Handbook of Ionospheric Models, edited by: Schunk, R. W., SCOSTEP Secretariat, Boulder, Colorado, USA, 1-25, 1996.

U.S. Congress: Report of the commission to assess United States national security, space management and organization, Public Law 106-65, Chapter II: Space: Today and the Future, 2122, 11 January 2001 (available from http://www.space.gov/docs/ fullreport.pdf), 2001.

Van Allen, J. A.: Energetic particles in the Earth's external magnetic field, in: Discovery of the Magnetosphere, edited by: Gillmor, C. S. and Spreiter, J. R., History of Geophysics, 7, AGU, Washington, D.C., 235-251, 1997.

Van Allen, J. A., Ludwig, G. H., Ray, E. C., and McIlwain, C. E.: Observation of high intensity radiation by satellites 1958 Alpha and Gamma, Jet Propulsion, 28, 588-592, 1958.

Van Allen, J. A., Frank, L. A., and O'Brien, B. J.: Satellite observations of the artificial radiation belt of July 1962, J. Geophys. Res., 68(3), 619-627, 1963.

Vampola, A.L.: Outer Zone Energetic Electron Environment Update, European Space Agency P.O. \#151351, 1996.

Vampola, A. L., Blake, J. B., and Paulikas, G. A.: A new study of the magnetospheric electron environment, J. Spacecraft and Rockets, 14, 690-695, 1977.

Verronen, P. T., Turunen, E., Ulich, Th., and Kyrölä, E.: Modelling the effects of the October 1989 solar proton event on mesospheric odd nitrogen using a detailed ion and neutral chemistry model, Ann. Geophys., 20, 1967-1976, 2002.

Verronen, P. T., Seppälä, A., Clilverd, M. A., Rodger, C. J., Kyrölä, E., Enell, C.-F., Ulich, Th., and Turunen, E.: Diurnal variation of ozone depletion during the October-November 2003 solar proton event, J. Geophys. Res., 110(A9), doi:10.1029/2004JA010932, 2005.

Vette, J.: The AE-8 trapped electron model environment, National Space Science Data Center, Greenbelt, Md., Rep. 91-24, 1991.

Voss, H. D., Walt, M., Imhof, W. L., Mobilia, J., and Inan, U. S.: Satellite observations of lightning-induced electron precipitation, J. Geophys. Res., 103, 11 725-11 744, 1998.

Wait, J. R. and Spies, K. P.: Characteristics of the Earth-ionosphere waveguide for VLF radio waves, NBS Tech. Note 300, Nat. Inst. of Stand. and Technol., Gaithersburg, Md., 1964.

Walt, M.: Introduction to geomagnetically trapped radiation, Cambridge University Press, Cambridge, 1994.

Walt, M.: Source and loss processes for radiation belt particles, in: Radiation Belts: Models and Standards, edited by: Lemaire, J. F., Heynderickx, D., and Baker, D. N., Geophysical Monograph, 97, 1-13, AGU, Washington, D.C., 1996. 